\title{
Downstream Movement of Moulting Whistling Swans, Thelon River, N.W.T.
}

by E. Kuyt, Canadian Wildlife Service, Fort Smith, N.W.T.

Whistling Swans are the most impressive of our waterfowl. Some of my most treasured observations are thcse made during early spring when a company of swans serenely glides to a resting spot on the first run-off water on the river ice in the tundra.

During my summer field work in 1963 in the Thelon Game Sanctuary the opportunity arose to band a number of moulting Whistling Swans (Olor columbianus). On a canoe trip on the Thelon River to the Hornby's Bend area, about 75 miles upstream from our camp at Lookout Point (see map), we encountered about 20 swans, including scme cygnets. On July 28 and 31,1963 , we were able to band 17 adult swans. We found these swans rather easy to capture. Our method was to chase the moulting birds downwind and then, with the swans only diving when we were very close to them, the man in the bow of the canoe could, with scme practice, often secure the bird on the first run by reaching over the gunwhale with one hand. We preferred

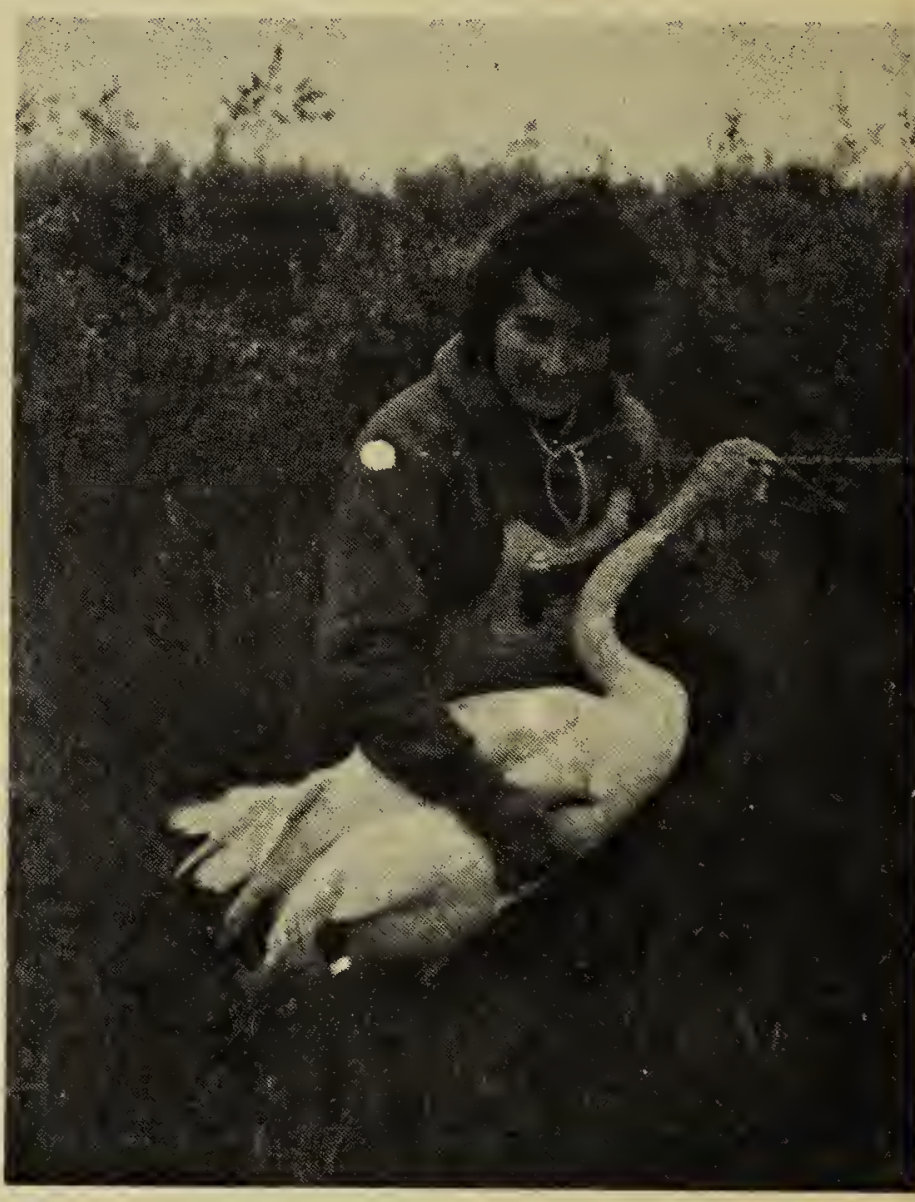

Photo by E. Kuyt Elsie Kuyt holding a $151 / 2$ lb. Whistling Swan July 18, 1963.

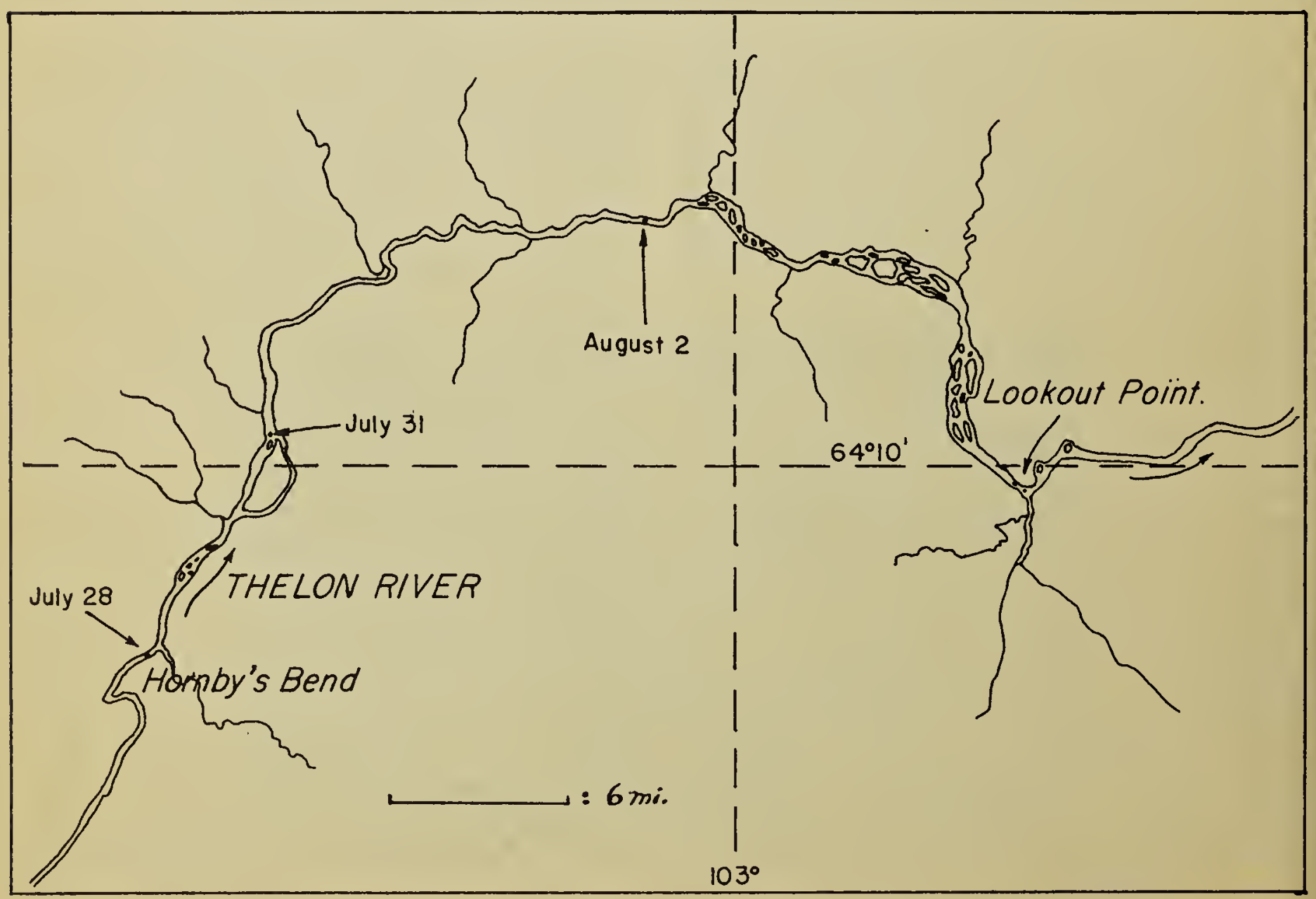


